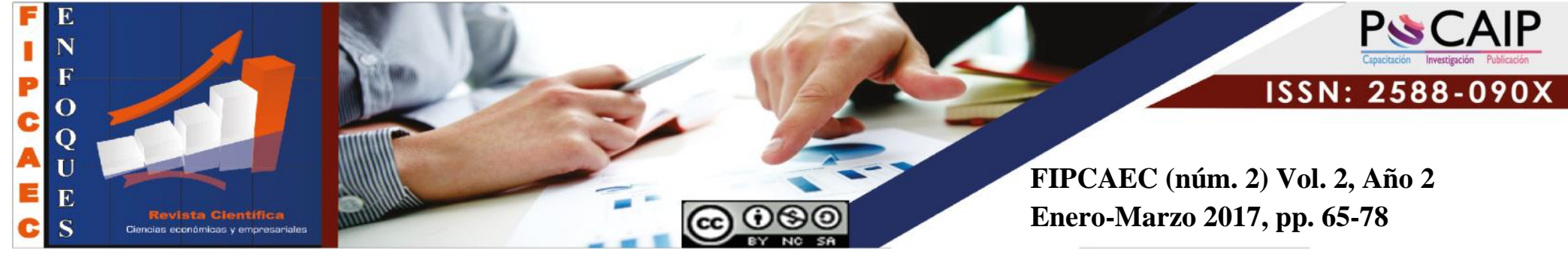

Recepción: 16/ 10/ 2016

Aceptación: 10 /12/2016

Publicación: 15/ 01/2017

\title{
Programación neuro lingüística (PNL) para el fomento de la comunicación
} asertiva en la gerencia educativa

\section{Neuro Linguistic Programming (NLP) for the promotion of assertive communication in educational management}

\section{Programação Neuro Linguística (PNL) para a promoção da comunicação assertiva na gestão educacional}

\author{
Juana Ojeda-San juan ${ }^{1}$ \\ juanacecilia@hotmail.com
}

\section{Correspondencia: juanacecilia@hotmail.com}

\footnotetext{
${ }^{1}$ Doctora en Ciencias. Mención Investigación, Doctora en Ciencias Sociales. Mención Gerencia, Especialista en Metodología de la Investigación, Magíster Scientiarum en Gerencia de la Educación Superior, Magíster Scientiarum en Filosofía, Licenciada en Filosofía, Licenciada en Educación. Mención Ciencias Matemáticas, Docente Titular a Dedicación Exclusiva de la Facultad Ciencias Humanas de la Universidad de Zulia, Maracaibo, Venezuela.
} 



\title{
Resumen
}

Se realizó una prueba de hipótesis, la población objeto de estudio estuvo conformada por 47 gerentes educativos de la ciudad de Manta - Ecuador. Al realizar la prueba T de Student para muestras independientes, se tiene que el grupo experimental obtuvo significancia de ,083 mientras que el grupo control ,000. Al compararse se evidencia que el grupo experimental tuvo cambio significativo, aceptándose la hipótesis afirmativa. El programa aplicado permite fortalecer el proceso comunicativo, desde una visión donde el gerente educativo pueda comprender que la asertividad como comunicación es el estilo ideal para propiciar el dialogo y acciones que conlleven a tener mayor eficacia en las actividades que se realizan con el fin de propiciar la consecución de metas propuestas bajo un clima de cordialidad en procura de elevar la productividad en la organización.

Descriptores: Psicolingüística, Psicología de la comunicación, comunicación interpersonal, Psicología de la comunicación.

\begin{abstract}
A hypothesis test was performed, the population under study was made up of 47 educational managers from the city of Manta - Ecuador. When performing the Student $\mathrm{T}$ test for independent samples, the experimental group obtained significance of 083 while the control group 000 . When comparing it is evident that the experimental group had significant change, accepting the affirmative hypothesis. The applied program makes it possible to strengthen the communicative process, from a vision where the educational manager can understand that assertiveness as communication is the ideal style to promote dialogue and actions that lead to greater effectiveness in the activities carried out in order to promote the achievement of proposed goals under a climate of cordiality in order to increase productivity in the organization.
\end{abstract}

Descriptors: Psycholinguistics, communication psychology, interpersonal communication, communication psychology. 


\section{Resumo}

Foi realizado um teste de hipótese, a população em estudo era composta por 47 gestores educacionais da cidade de Manta - Equador. Ao realizar o teste T de Student para amostras independentes, o grupo experimental obteve significância de 083 enquanto o grupo controle 000. Ao comparar, fica evidente que o grupo experimental apresentou alteração significativa, aceitando a hipótese afirmativa. O programa aplicado possibilita o fortalecimento do processo comunicativo, a partir de uma visão em que o gestor educacional pode entender que assertividade como comunicação é o estilo ideal para promover o diálogo e ações que levam a maior efetividade nas atividades realizadas para promover a consecução dos objetivos propostos em um clima de cordialidade, a fim de aumentar a produtividade na organização.

Descritores: Psicolinguística, Psicologia da comunicação, Comunicação interpessoal, Psicologia da comunicação.

\section{Introducción}

Las organizaciones cada día van en búsqueda de alternativas que le permitan fomentar una mejor formación en su capital humano, de ese modo, podrán encaminarse hacia la consolidación del éxito en un mundo donde la competitividad cada vez tiene mayor énfasis, esto trae consigo, que el capital humano deba prepararse cada día para estar a la altura de las exigencias de un mercado que se hace exigente y riguroso.

En este sentido, el capital humano de las organizaciones educativas no escapa a esta realidad, específicamente el personal que se dedica a labores gerenciales, por cuanto debe transmitir una serie de información hacia sus subalternos con el objeto de que estos puedan cumplir con los objetivos propuestos en la organización.

Esta información que transmiten es posible a un acto comunicativo, el cual por tratarse de una comunicación entre personas, lleva consigo emociones, afectos, percepciones tanto del emisor como el receptor; todo este proceso comunicativo si es bien llevado puede traer consigo beneficios para la organización educativa, por el contrario sí no se hace del todo efectivo puede traer consecuencias que perjudican la productividad de la organización. 
En este sentido, los gerentes educativos deben buscar alternativas que le ayuden a incrementar su comunicación con el resto del equipo con el cual deben trabajar en la consolidación de los objetivos propuestos por la organización educativa. Por lo tanto, debe darse una comunicación que fomente el mayor de los éxitos posibles, este tipo de comunicación puede ser la asertiva, porque simplemente este estilo de comunicación permite que el emisor se encuentre en un estado óptimo para difundir un mensaje, es decir, no es pasivo ni agresivo a la hora de transmitir el mismo. Sin embargo, desarrollar una comunicación asertiva no siempre resulta fácil, muchas veces se requiere de un entrenamiento para poder lograr este estilo de comunicación, ante esto Berverly (2009) señala que la comunicación asertiva:

Es una forma de expresión consciente, congruente, clara, directa y equilibrada, cuya finalidad es comunicar nuestras ideas y sentimientos o defender nuestros legítimos derechos sin la intención de herir, o perjudicar, actuando desde un estado interior de autoconfianza, en lugar de la emocionalidad limitante típica de la ansiedad, la culpa o la rabia (p. 37).

Como se observa y ante lo cual se ha comentado, la comunicación asertiva requiere de un entrenamiento para poder realizarla de un modo efectivo, es de acotar, que esta comunicación pertenece al enfoque cognitivo - conductual de la psicología, la cual tiene una serie de técnicas que permiten el desarrollo efectivo de este estilo comunicativo.

Por lo que se hace necesario que la persona tenga un entrenamiento en tal enfoque, pero sobre todo en relación a la comunicación asertiva, sin embargo, este entrenamiento por sí solo es probable que no dé el resultado esperado, por cuanto se hace necesario que la persona posea unas cualidades que le permitan auto conocerse, auto controlarse, para comunicar asertivamente el mensaje que pretende transmitir.

En este sentido, los gerentes educativos deben tener claro que no basta solo con entrenarse en comunicación asertiva para lograr un mejor desempeño en la organización, sino, que este entrenamiento debe ir acompañado de otras alternativas que permitan fomentar una personalidad con las cualidades necesarias para poder aplicar efectivamente la comunicación asertiva.

En este orden de ideas, puede tomarse como alternativa para fomentar una comunicación asertiva en los gerentes educativos, la programación neuro lingüística (PNL) por cuanto está básicamente es un modelo de comunicación interpersonal que trabaja en pro de la consolidación de acciones exitosas a partir de la propia subjetividad de la persona. 
En concordancia con lo planteado, se tiene que Mohl (2008), afirma que "la PNL (Programación Neurolingüística) constituye un modelo, formal y dinámico de cómo funciona la mente y la percepción humana, cómo procesa la información y la experiencia y las diversas implicaciones que esto tiene para el éxito personal" (p. 14). En consideración de lo que se trata, es que los gerentes educativos puedan tener la oportunidad de programar sus pensamientos, sus acciones, pero sobre todo la comunicación que van a emitir a sus subalternos, por lo que se hace interesante trabajar en la conjunción entre programación neuro lingüística y comunicación asertiva.

Debido que ambas procuran establecer una comunicación que conduzca al éxito individual pero que este a su vez beneficie al colectivo, de lo que se trata entonces es formar a los gerentes educativos en programación neuro lingüística para que puedan fomentar una mejor personalidad y desde esta perspectiva desarrollen una óptima comunicación asertiva.

En este sentido, Rivas (2008) enuncia que "la principal tarea de un gerente educativo, al ejecutar planes y activar programas sociales, es integrar los recursos humanos de la institución en un equipo de trabajo participante orientado al logro de los objetivos de la organización" (p. 53). Es evidente que en este proceso de integración se hace necesario fomentar una comunicación que permita que el mensaje llegue con claridad y con la influencia pertinente a todos los receptores, para que éstos puedan abocarse al trabajo en pro de los objetivos planteados.

En este orden de ideas, es conveniente resaltar la importancia que tiene la comunicación para promover una organización educativa eficaz, comprometida con los actores sociales que hacen vida en torno a ella, por lo tanto, el trabajar en PNL y comunicación asertiva podría contribuir en la optimización de la comunicación promovida desde la gerencia educativa. En relación a lo planteado, Velázquez (2008) manifiesta que,

Lograr el entendimiento entre las personas es una habilidad que debe cultivar todo gerente, motivando a su personal a la participación y fomentando el trabajo en equipo para la resolución de problemas. Desde ésta perspectiva, toda institución debe priorizar dentro de su estructura organizacional un sistema de comunicaciones e información que dinamice los procesos en el ámbito interno y externo, que vivifiquen la entidad y la proyecten hacia su área de influencia. De allí, que es necesario que los gerentes de los planteles educativos propulsen los cambios y las resoluciones educativas incentivando en su personal en los procesos que implican una red social intrainstitucional (p. 3). 
Como se ha venido planteando, desde la gerencia educativa debe promoverse una comunicación que sea capaz de promover la participación activa del personal de la organización; sin embargo, se ha observado en visitas realizadas a los institutos educativos de la ciudad de Manta - Ecuador, que existen gerentes educativos que no promueven una comunicación asertiva en pro de gestionar un trabajo efectivo en sus subalternos.

Esta situación ha conllevado a iniciar una serie de entrevistas no formales con personal docente, administrativo y obrero, para conocer cuál es la percepción que tienen sobre el estilo de comunicación que implementan los gerentes educativos. En este sentido, un 36\% de las personas con las cuales se ha tenido contacto, manifiestan que los gerentes educativos tienden a tener un estilo agresivo a la hora de transmitir una comunicación a su personal.

Esta situación, puede traer consecuencias como la desmotivación del personal, debido que el estilo agresivo arremete muchas veces contra la dignidad del receptor, sobre todo sí este estilo comunicativo se ejerce en público o delante de terceras personas, lo que a su vez puede influir negativamente en la estima de la persona. Otro factor negativo que puede traer consigo la utilización de un estilo agresivo por parte de los gerentes educativos, es que pueden crear sumisidad y rebeldía en su personal, lo que a su vez puede ocasionar descontento, clima organizacional y laboral no acorde para desarrollar óptimamente el trabajo adscrito a cada persona.

Por lo tanto, la profundización del estilo agresivo puede conllevar a que las personas afectadas se establezcan en un estilo comunicativo pasivo, lo cual no es óptimo desde el punto de vista de la relación intra e interpersonal, porque simplemente no tienden a la asertividad, por otro lado, el personal de las organizaciones educativas, también pudiesen ejercer un estilo agresivo en la comunicación con los gerentes educativos, producto de activarse el mecanismo de defensa natural de todo ser humano.

En fin se hace necesario tomar correctivos para subsanar esta situación, porque si no se corre el riesgo de que pueda incrementarse y simplemente las organizaciones educativas tenderían a convertirse en lugares donde la cohabitibilidad laboral simplemente no sería la más óptima para desempeñar las funciones que a cada personal le corresponde.

$\mathrm{Al}$ proseguir con las entrevistas no formales con el personal de las organizaciones educativas, se evidenció que un 36\% de las personas con las cuales se dialogó, manifestaron que sus derechos 
son vulnerados por los gerentes educativos a la hora de comunicarse con ellos, debido que al expresarse en un tono autoritario, muchas veces no permiten que la otra persona pueda manifestar su punto de vista con lo cual se van originando fisuras en las relaciones interpersonales de la organización.

Otro $35 \%$ de las personas entrevistadas no formalmente, manifestaron que los gerentes educativos no promueven el reconocimiento positivo por los aciertos que realizan en pro de la consolidación de las metas de la organización educativa, en este sentido, tienden a resaltar las situaciones negativas que puedan ocurrir, lo que trae consigo problemas emocionales en el personal que se ve afectado.

Partiendo de las problemáticas expuestas y en pro de que no se consoliden, sino, que por el contrario se puedan minimizar en su totalidad, surge la preocupación por realizar un trabajo investigativo que permita trabajar en la solución de tales conflictos; es así, que se formulan las siguientes hipótesis:

Alterna H1: La formación en programación neuro lingüística (PNL) para el fomento de la comunicación asertiva en la gerencia educativa, funcionó significativamente.

Nula H0: La formación en programación neuro lingüística (PNL) para el fomento de la comunicación asertiva en la gerencia educativa, no funcionó significativamente.

\section{Desarrollo}

\section{Programación neurolingüística (PNL)}

En referencia a la programación neurolinguiística (PNL) Martínez (2008) señala constituye un modelo, formal y dinámico de cómo funciona la mente y la percepción humana, cómo procesa la información y la experiencia y las diversas implicaciones que esto tiene para el éxito personal. Con base en este conocimiento es posible identificar las estrategias internas que utilizan las personas de éxito, aprenderlas y enseñarlas a otros (modelar); para facilitar un cambio evolutivo y positivo.

La Programación Neurolingüística, por analogía con el ordenador, utiliza los patrones universales de comunicación y percepción que tenemos para reconocer e intervenir en procesos diversos 
(aprendizaje, terapia, afrontamiento del estrés, negociación, gestión de conflictos, superación de fobias, etc...). El campo de trabajo es tan amplio como lo es el de las relaciones interpersonales.

La PNL es el estudio de lo que percibimos a través de nuestros sentidos (vista, oído, olfato, gusto y tacto), cómo organizamos el mundo tal como lo percibimos y cómo revisamos y filtramos el mundo exterior mediante nuestros sentidos. En este sentido, O’Connor y Seymour (2008), la definen como: "Un sistema para preparar (programar), sistemáticamente nuestra mente (neuro), y lograr que comunique de manera eficaz lo que pensamos con lo que hacemos (linguiística), logrando así una congruencia y comunicación eficaz a través de una estrategia que se enfoca al desarrollo humano". Por lo tanto, la manera como nos comunicamos en cierto modo proviene de lo que se tiene guardado en la mente, lo cual es exteriorizado por el ser humano.

De acuerdo a Mohl (2008), "la PNL (Programación Neurolingüística) constituye un modelo, formal y dinámico de cómo funciona la mente y la percepción humana, cómo procesa la información y la experiencia y las diversas implicaciones que esto tiene para el éxito personal" (p. 14). De ahí que Mohl (Op. Cit.), afirme que por medio de este modelo se hace posible identificar las estrategias internas que utilizan las personas de éxito, aprenderlas y enseñarlas a otros (modelar); lo que permite un cambio favorable a la persona que la practique.

La Programación Neurolingüística, utiliza los patrones universales de comunicación y percepción que el ser humano posee para reconocer e intervenir en procesos diversos (aprendizaje, terapia, afrontamiento del estrés, negociación, gestión de conflictos, superación de fobias, entre otros). Todo con el propósito de brindarle a la persona la posibilidad de explotar al máximo sus capacidades internas y llevarlas a un proceso de manifestación exterior que se traduce en un desarrollo personal integral que le brinda la oportunidad de crecer día a día hasta convertirse en una persona exitosa en el ámbito donde se desenvuelve.

Por lo tanto, la PNL trabaja como el ser humano procesa y brinda respuestas a los diversos estímulos que percibe del medio ambiente sean estos positivos o negativos, de ahí que la PNL estudia lo que la persona percibe a través de los sentidos (vista, oído, olfato, gusto y tacto), y cómo esta organiza la información que percibe, cómo analiza y filtra el mundo exterior mediante los sentidos.

Mohl (2008), plantea que la PNL se puede utilizar para desarrollar de manera rápida y eficaz un proceso de aprendizaje y así superar una situación de estrés, de conflicto, negociar con mayor 
ventaja frente a nuestros adversarios. De ahí que permita conocer la percepción de las otras personas a quienes tenemos enfrente o a nosotros mismos. Es un complemento en el desarrollo de la Inteligencia emocional. Entre otras cosas, la PNL le permite al ser humano:

- Aumentar de manera notable y rápida la autoconfianza.

- Mejorar las relaciones interpersonales.

- Desarrollar el crecimiento personal y profesional hacia el éxito.

- Nos permite convertirnos en quien deseamos y queremos ser.

- Sirve para reducir el estrés.

- Negociar y solucionar conflictos de manera positiva.

De ahí, la importancia de fomentar la PNL en los gerentes educativos con el fin que los mismos, tengan la oportunidad de contar con herramientas que le permitan fomentar una mejor comunicación entre los miembros de su organización, y así, elevar la productividad de la misma.

\section{Comunicación asertiva}

Existen diversos tipos o modelos de comunicación, siendo uno de ellos la comunicación asertiva, definida por Gonzales (2009) como:

Una forma de expresión consciente, congruente, clara, directa y equilibrada, cuya finalidad es comunicar nuestras ideas y sentimientos o defender nuestros legítimos derechos sin la intención de herir, o perjudicar, actuando desde un estado interior de autoconfianza, en lugar de la emocionalidad limitante típica de la ansiedad, la culpa o la rabia (p. 67).

En este sentido, se tiene que la comunicación asertiva permite proyectar la comunicación de un modo que el receptor pueda entender del mejor modo posible lo que se pretende comunicar. La persona con comunicación asertiva, tiende a decir las cosas en el momento preciso, bajo preceptos de prudencia y empatía, cualidades que coadyuvan a que la persona con asertividad pueda incrementar la calidad del mensaje que transmite.

La comunicación asertiva en las organizaciones se constituye en una alternativa que permite orientar hacia una mayor productividad a la empresa, por cuanto, al poder establecerse una 
asertiva comunicación, más digerible y entendible se hace el mensaje, de ese modo, cada miembro de la organización puede cumplir con su rol de un modo efectivo.

Por lo tanto, se hace necesario fomentar alternativas que propicien en la empresa la comunicación asertiva, de ahí que la PNL pueda constituirse en una opción válida para tal fin, debido que educa al ser humano para que pueda comunicarse de un mejor modo, en este sentido, tanto PNL como comunicación asertiva, se constituyen en un binomio para el crecimiento de la organización, debido que permiten fomentar la comunicación como pilar básico para la consolidación de la misma.

Sin embargo, es importante acotar que dentro de la comunicación existen los siguientes estilos: Existen tres estilos básicos de comunicación diferenciados por la actitud que revelan hacia el interlocutor: pasivo, asertivo y agresivo.

Pasividad o no-asertividad. Es aquel estilo de comunicación propio de personas que evitan mostrar sus sentimientos o pensamientos por temor a ser rechazados o incomprendidos o a ofender a otras personas. Infravaloran sus propias opiniones y necesidades y dan un valor superior a las de los demás.

Agresividad. Este estilo de comunicación se sitúa en un plano opuesto a la pasividad, caracterizándose por la sobrevaloración de las opiniones y sentimientos personales, obviando o incluso despreciando los de los demás.

Asertividad. Es aquel estilo de comunicación abierto a las opiniones ajenas, dándoles la misma importancia que a las propias. Parte del respeto hacia los demás y hacia uno mismo, aceptando que la postura de los demás no tiene por qué coincidir con la propia y evitando los conflictos sin por ello dejar de expresar lo que se quiere de forma directa, abierta y honesta.

Como puede observarse, se hace necesario fomentar la asertividad como estilo predominante en la persona, para que así, pueda fomentarse un clima de cordialidad, empatía, sinergia, las cuales promuevan una mayor productividad individual y grupal en la organización. Por lo tanto, es tarea de los gerentes educativos promover una actitud asertiva no solo en sí mismos, sino, en las personas que se encuentran en la organización, de ese modo, la misma podrá consolidar las metas propuestas en la planificación organizacional. En este sentido, se hace necesario conocer alternativas que permitan fomentar la asertividad, para lo cual puede fusionarse la PNL con la 
comunicación asertiva, en procura de generar un cambio en lo personal que produzca frutos hacia lo colectivo.

\section{Metodología de la investigación}

La investigación fue de tipo explicativa, Hernández Sampieri, Fernández Collado \& Baptista (2014), la definen “como aquellos estudios que van más allá de la descripción de los fenómenos”. Para el análisis estadístico del pre y post test se aplicó la prueba T de Student. Construyéndose las siguientes hipótesis:

Alterna H1: La formación en programación neuro lingüística (PNL) para el fomento de la comunicación asertiva en la gerencia educativa, funcionó significativamente.

Nula H0: La formación en programación neuro lingüística (PNL) para el fomento de la comunicación asertiva en la gerencia educativa, no funcionó significativamente.

La población objeto de estudio estuvo conformada por 47 gerentes educativos de la ciudad de Manta - Ecuador, la muestra que participó en el grupo experimental (tratamiento) fue de 23 personas quienes conformaron el grupo RG1, mientras que otros 24 conformaron el grupo control o RG2 (no se les aplicó tratamiento).

\section{Resultados de la investigación}

\section{Cuadro 1}

Efectividad del tratamiento aplicado

\begin{tabular}{|c|c|c|c|c|c|c|}
\hline \multicolumn{7}{|c|}{ Prueba para una muestra } \\
\hline & \multicolumn{6}{|c|}{ Valor de prueba $=5$} \\
\hline & \multirow[b]{2}{*}{$t$} & \multirow[b]{2}{*}{$\mathrm{gl}$} & \multirow[b]{2}{*}{ Sig. (bilateral) } & \multirow{2}{*}{$\begin{array}{l}\text { Diferencia de } \\
\text { medias }\end{array}$} & \multicolumn{2}{|c|}{$\begin{array}{c}95 \% \text { de intervalo de confianza } \\
\text { de la diferencia }\end{array}$} \\
\hline & & & & & Inferior & Superior \\
\hline RG1 & $-1,817$ & 22 &, 083 &,- 13043 &,- 2793 &, 0185 \\
\hline RG2 & $-14,270$ & 23 &, 000 & $-2,75000$ & $-3,1487$ & $-2,3513$ \\
\hline
\end{tabular}


Se ejecutó una prueba de hipótesis utilizando un nivel de significancia de 5\%. Las hipótesis planteadas son:

Alterna H1: La formación en programación neuro linguística (PNL) para el fomento de la comunicación asertiva en la gerencia educativa, funcionó significativamente.

Nula H0: La formación en programación neuro lingüística (PNL) para el fomento de la comunicación asertiva en la gerencia educativa, no funcionó significativamente.

Al realizar la prueba $\mathrm{T}$ de Student para muestras independientes, se tiene que el grupo experimental obtuvo significancia de ,083 mientras que el grupo control ,000.

Al compararse se evidencia que el grupo experimental tuvo cambio significativo, aceptándose la hipótesis afirmativa:

Alterna H1: La formación en programación neuro linguística (PNL) para el fomento de la comunicación asertiva en la gerencia educativa, funcionó significativamente.

\section{Conclusiones}

El programa aplicado permite fortalecer el proceso comunicativo, desde una visión donde el gerente educativo pueda comprender que la asertividad como comunicación es el estilo ideal para propiciar el dialogo y acciones que conlleven a tener mayor eficacia en las actividades que se realizan con el fin de propiciar la consecución de metas propuestas bajo un clima de cordialidad en procura de elevar la productividad en la organización.

Así mismo, los docentes en el rol de gerencia educativa, deben formarse constantemente en áreas relacionadas a la psicología y crecimiento emocional, con la finalidad de promover relaciones interpersonales asertivas, lo cual permite promover el reconocimiento del trabajo realizado por la otra persona, motivándose a generar un trabajo cada día de mayor actividad, de ese modo, las instituciones educativas transitan progresivamente a la consecución de un liderazgo organizacional dispuesto a trabajar desde las potencialidades de las personas en aras de reconocer la persona como centro de la sociedad, siendo importante emplear estrategias en mejora de las debilidades, así se podrán formar equipos de trabajo bajo una visión cooperativa de accionar gerencial. 


\section{Referencias consultadas}

1. Berverly, H. (2009). Sea asertivo. Ediciones gestión 2000. Madrid. España

2. Gonzales (2009). Comunicación asertiva. Documento en línea. Recuperado de http://prezi.com/heh9jsilixu9/comunicacion-verbal-y-no-verbal/

3. Hernández Sampieri, R., Fernández Collado , C., \& Baptista , L. (2014). Metodología de la investigación . México: Editorial Mc - Graw - Hill Interamericana. Sexta edición.

4. Martínez, J. (2008). PNL una herramienta para mejorar su vida. Recuperado de http://www.liderazgoymercadeo.com/articulocont.asp?a=153

5. Mohl, A. (2008). El aprendiz de brujo. Manual de ejercicios de PNL. Recuperado de http://sermejorlibros.blogspot.com/search/label/El\%20aprendiz\%20de\%20brujo

6. Rivas, S. (2008). Estrategias comunicacionales dirigidas al docente líder. Trabajo de grado. Universidad Gran Mariscal de Ayacucho. Venezuela.

7. Velásquez, E. (2008). Comunicación en la gerencia educativa. Recuperado de http://edisvelasquez.obolog.com/comunicacion-gerencia-educativa-78304

\section{References consulted}

1. Berverly, H. (2009). Be assertive Editions management 2000. Madrid. Spain

2. Gonzales (2009). Assertive communication. Online document Recovered from http://prezi.com/heh9jsilixu9/comunicacion-verbal-y-no-verbal/

3. Hernández Sampieri, R., Fernández Collado, C., \& Baptista, L. (2014). Investigation methodology . Mexico: Editorial Mc - Graw - Interamerican Hill. Sixth edition.

4. Martínez, J. (2008). NLP a tool to improve your life. Recovered from http://www.liderazgoymercadeo.com/articulocont.asp?a=153

5. Mohl, A. (2008). The sorcerer's apprentice. NLP exercise manual. Recovered from http://sermejorlibros.blogspot.com/search/label/El\%20aprendiz\%20de\%20brujo 
6. Rivas, S. (2008). Communication strategies aimed at the teacher leader. Degree work. Grand Marshal University of Ayacucho. Venezuela.

7. Velásquez, E. (2008). Communication in educational management. Recovered from http://edisvelasquez.obolog.com/comunicacion-gerencia-educativa-78304

C2017 por el autor. Este artículo es de acceso abierto y distribuido según los términos y condiciones de la licencia Creative Commons Atribución-NoComercial-Compartirlgual 4.0 Internacional (CC BY-NC-SA 4.0) (https://creativecommons.org/licenses/by-nc-sa/4.0/). 